\title{
Health Related Quality of Life of Cancer Patients in Ethiopia
}

\author{
Tadesse Melaku Abegaz $\mathbb{D}$, Asnakew Achaw Ayele $\mathbb{D}$, and Begashaw Melaku Gebresillassie $\mathbb{D}$
}

College of Medicine and Health Sciences, School of Pharmacy, Department of Clinical Pharmacy,

University of Gondar, Gondar, Ethiopia

Correspondence should be addressed to Tadesse Melaku Abegaz; abegaztadesse981@gmail.com

Received 22 December 2017; Accepted 8 March 2018; Published 15 April 2018

Academic Editor: James L. Mulshine

Copyright (C) 2018 Tadesse Melaku Abegaz et al. This is an open access article distributed under the Creative Commons Attribution License, which permits unrestricted use, distribution, and reproduction in any medium, provided the original work is properly cited.

\begin{abstract}
Background. Neoplasm, AKA cancer (Ca), is associated with major morbidity and mortality. Aim. Measurement of health related quality of life (HRQoL) of Ca patients is uncommon in Ethiopia. The present study determined the HRQoL and its determinants among people living with $\mathrm{Ca}$ in north Ethiopia. Methods. A prospective hospital based study was conducted from 1 January 2017 to 30 August 2017 on Ca patients attending cancer treatment center of University of Gondar Teaching Hospital. The European Organization for Research and Treatment of Cancer Questionnaire version 3 was utilized to collect the data. The rate of QoL was presented using means with standard deviation $( \pm S D)$. Binary logistic regression was employed to determine factors associated with HRQoL. Result. The present study is based on the findings from 150 subjects. The rate of QoL was 52.7 (20.1) (mean \pm SD). The highest functional status was emotional functioning 61 (25.5). Patients with no disease metastasis, 92.1 (5.1), had high QoL as compared to metastasis, $22.1(18.9)(p=0.03)$. Patients with affected physical functioning have a $20 \%$ reduction in QoL and Adjusted Odds Ratio (AOR) of 0.794 [0.299-891]. Patients with low satisfaction level with the provided care, 0.82 [0.76-0.93], and those with unmet needs, 0.85 [0.80-0.95], experienced reduced level of HRQoL. Conclusion. Health related quality of life of cancer patients was found to be low in Ethiopia. Patients with limited rate of disease metastasis had improved HRQoL. Further, the unmet needs of Ca patients and the level of satisfaction with the overall care were found to influence the extent of HRQoL. Therefore, early detection of neoplasm to arrest metastasis is warranted in order to achieve better QoL. In addition, addressing the unmet needs of these patients and ensuring higher satisfaction rate are recommended to maintain adequate HRQoL.
\end{abstract}

\section{Introduction}

Neoplasm, AKA cancer (Ca), is associated with major morbidity and mortality in the world. A twenty-five-year systematic analysis of cancer registry from 195 countries demonstrated that there were 17.5 million cancer cases and 8.7 million deaths in the year 2015 worldwide [1]. Over a ten-year period (2005-2015), cancer cases increased by one-third (33\%). The longevity of the general population (16\%) and population density (13\%) contributed to this magnitude. Breast cancer is the most commonly isolated cancer and the leading cause of mortality among women. Globally, it is attributed to one-fourth of the total cancer diagnosis and 14\% of cancer deaths. Lung cancer is the leading malignancy site in males and makes $17 \%$ of the total new cancer incidence and $23 \%$ of the gross cancer deaths [2]. In Africa, cancer mortality was estimated to be 542,000 with a diagnosis of 715,000 new cancer cases as of 2008 [3].
Cancer is emerging as a formidable challenge in low income countries that have limited logistic to protect the health of citizens. In developing countries, the burden of $\mathrm{Ca}$ overlaps with the magnitude of infectious diseases including HIV/AIDS, tuberculosis, hepatitis virus, and human papilloma virus which can contribute to the pathogenesis of Ca. The lack of early detection and timely treatment would aggravate the situation in these nations [4]. In Ethiopia, cancer belongs to the second most common noncommunicable disease (NCD) only next to cardiovascular disorders [5]. In Gondar University Hospital, the number of new cases seen has increased following the establishment of new cancer treatment center. Tefera et al. 2016 reported that the top three cancer types were lymphoma (17.2\%), cervical cancer (15.2\%), and breast cancer (14.1\%), respectively [6].

While treating cancer patients, we usually set different end points to measure the effectiveness of our intervention. Some of the parameters are regarded as primary end points 
and coprimary and surrogate (intermediate) endpoints. These measurements include Overall Survival (OS), ProgressionFree Survival (PFS), Overall Radiographic Response (ORR), and health related quality of life (HRQoL). OS is an objective primary endpoint which measures all causes of death. But, it does not determine the exact impact of treatment [7]. PFS is an intermediate end point which predicts OS rate within short period of time and with reduced cost. However, PFS does not imply the clinical advantage of the treatment for the patient since the PFS is achieved in the expense of treatment toxicity and decline in HRqol. Like PFS, ORR directly measures the extent of the tumor through radiography. Nonetheless, it lacks reproducibility due to observer bias. Moreover, the above measures do not incorporate the patient perspective. On the other hand, HRqol is self-perceived approach to evaluate patients' view of their own health status [7]. The definition of HRqol remains different among different literatures. HRQoL can be defined as "how well individuals function on some predefined activities in their life and wellbeing in physical, mental, and social domains of health." Wellbeing refers to an individual's subjective feelings $[7,8]$. It is assessed by a standard structured questionnaire called Quality of Life Questionnaire (QLQ) prepared by the European organization for research and treatment of cancer. It has been used for clinical trials. But, recently it is introduced in nontrial studies $[9,10]$.

The significant number of people living with cancer (PLWCa) rarely achieves reemission with chemotherapy, surgery, or radiotherapy. In these patients, our goal is to improve their quality of life and to promote their functioning. HERqol is an important tool used to evaluate the functioning of our patients. Assessment of HERqol is also helpful to pass shared decision between the patient and the clinician regarding the treatment. But, it has not been implemented in our setup so far. Therefore, the present study aimed to investigate cancer patients' health related quality of life at Gondar University Hospital Cancer Center.

\section{Methods}

2.1. Study Setting and Area. University of Gondar Referral Hospital (UoGRH) is a teaching hospital located in Gondar Town, northwest Ethiopia. Gondar is $748 \mathrm{kms}$ away from the capital, Addis Ababa. The Gondar Cancer Center was established in January 2015 with few dedicated individuals. It is regarded as the second treatment center in the country. More than 600 patients visit the center for chemotherapy and screening. It is run by few physicians and nurses who have gained adequate training on the discipline. The inpatient ward contains ten beds in which chemotherapy is administered in each cycle. The cytotoxic admixture and administration are carried out by nurses. However, there is no radiotherapy service in the hospital so far.

2.2. Population. All cancer patients who were admitted to oncology ward of UoGRH during the study period were our source populations, whereas patients above the age of 18 years were the study population.
2.3. Study Design and Period. A prospective hospital based cross-sectional study was conducted from 1 January 2017 to 30 August 2017.

2.4. Inclusion and Exclusion Criteria. Patients who were receiving therapy and are above 18 years old were included. Those who did not consent for the study and are unable to respond for the questions were excluded.

2.5. Sample Size Determination and Sampling Technique. All cancer patients were consecutively included in the study based on inclusion and exclusion criteria during the study period.

2.6. Study Variables. Our dependent variable was the rate of HRQoL. Independent variables include sociodemographic characteristics of the patient including age and gender, functional status, and symptom scales.

2.7. Data Collection Methods. Data was collected by two trained clinical nurses. A structured questionnaire which contained of 30 items was adopted from the Quality of Life Questionnaire (QLQ-30) version 3 which is the standard version currently. It was released in 1993 [9]. The questionnaire contains five multi-item functional status scales (physical, role, social, emotional, and cognitive) and 9 symptoms scales (pain, fatigue, financial impact, appetite loss, and nausea/) and two global health status items.

The scoring of the findings was based on EORTC QLQ30 scoring manual $[10,11]$. The scales are rated in terms of percentage. A high score in functional scale and global health status denotes high health status, respectively. But, for a symptom scale high score represents sever symptomatology.

2.8. Data Quality Control Technique. Data collectors were trained intensively on contents of the questionnaire, data collection methods, and ethical concerns. The questions were translated into Amharic so as to maintain unbiased response. The filled questionnaire was checked daily for completeness by the principal investigator. The reliability (psychometric property) of the tool was evaluated and demonstrated a Cronbach alpha value of 0.871 . The content of the questionnaire was reviewed by senior experts.

2.9. Data Analysis. All the statistical data were carried out using Statistical Package for Social Sciences (SPSS), version 20 (SPSS Inc., Cary, NC, USA). Descriptive statistics was presented using means with standard deviation $( \pm \mathrm{SD})$ and percentages (\%). $p$ values were kept $<0.05$ with $95 \%$ confidence interval. Bivariate analysis was applied to investigate the correlation of independent variables. Binary logistic regression was employed to determine associated factors. One-way analysis of variance has been employed to assess the mean difference in quality of life.

\section{Results}

3.1. Sociodemographic and Clinical Characteristics of Patients. The present study was based on the findings from 150 
subjects. All of the patients who attended the cancer treatment center responded to the questionnaire. The mean age of the respondents was 46.8 (14.5). More than half of the patients were females 83 (52.9\%). Above forty percent of them did not have formal education 69 (43.9\%). The average monthly income was $1336.1 \pm 240.3$ Ethiopian birr $(\$ 49.48$ $\pm 8.9, \$=27.175 \mathrm{ETB})$. Nearly forty percent of cases were metastasis 65 (41.4). The mean duration of the disease was $13.4 \pm 12.1$ months. The most common $\mathrm{Ca}$ include breast Ca 37 (24.7) followed by blood related $\mathrm{Ca} 36$ (24). The frequently prescribed medications include leucovorin (79), 5fluorouracil (68), and cisplatin (47), respectively (Table 1).

3.2. Global Health Status, Functional Scales, and Symptom Scales. The rate of quality of life based on global health status (GHS) was 52.7 (20.1). The highest FS was emotional functioning (EF) 61 (25.5) followed by cognitive functioning $59.31(43.6 \%)$. The physical functioning state of the patients was 53.27 (22.9) whereas social functioning (SF) and role functioning (RF) accounted to 46.31 (25.5) and 43.32 (26.7), respectively. Nausea and vomiting were the most annoying symptom, 43.3 (23.1) followed by 42.1 (33.3), and fatigue, 41.47 (24.5) (Table 2).

3.3. The Mean Difference in QoL Scales versus Sociodemographic Characteristics. RF was found to be different based on marital status $(p=0.02)$. According to post hoc analysis, the difference was found to be between single marital status, 43 (31.6), and divorced, $1.2(2.3)(p=0.01)$, and married, 36.7 (29.8), and divorced ( $p=0.03$ ). The mean difference of GHS was significant for disease metastasis. Accordingly, patients with no disease metastasis, 92.1 (5.1), had high GHS as compared to metastasis, $22.1(18.9)(p=0.03)$. The mean difference of EF was also significant in terms of disease metastasis, 34.1 (25.5) versus $53.2(25.3)(p=0.04)$. GHS was also different for patients who underwent surgical procedure, $82.8(4.9)$ and $24.5(19.5)(p=0.01)$ (Table 3).

3.4. Multinomial Regression Indicating Factors Affecting Quality of Life. Binary logistic regression indicated that patients with affected physical functioning have a $20 \%$ reduction in quality of life of AOR of 0.794 [0.299-891]. Patients with no history of vomiting were 2.5 more likely to have good QoL as compared to patients with vomiting history of AOR of 2.655 [1.839-8.397]. Patients whose social functioning is not affected more than three times are more likely to have good QoL of 3.637 [1.838-8.300]. Patients with unaffected EF had 4.5 times good HRQoL as compared to affected HRQoL of 4.426 [2.890-6.613]. Patients with low satisfaction level with the provided care of 0.82 [0.76-0.93] and those with unmet needs of 0.85 [0.80-0.95] experienced reduced level of HRQoL (Table 4).

\section{Discussion}

$\mathrm{Ca}$ and its treatment strategies substantially affect HRQoL of patients. HRQoL is viewed as one of treatment end points in these individuals. Estimation of HRQoL of patients
TABLE 1: Sociodemographic and clinical characteristics of cancer patients attending UoGRH.

\begin{tabular}{|c|c|}
\hline Variables & $N(\%)$ \\
\hline Age & $46.8(14.5)$ \\
\hline Females & $83(52.9)$ \\
\hline \multicolumn{2}{|l|}{ Occupation } \\
\hline Nongovernmental & $14(8.9)$ \\
\hline Private employee & $36(22.9)$ \\
\hline Government employee & $20(2.7)$ \\
\hline Agriculture & $56(37.33)$ \\
\hline Retire & $24(16)$ \\
\hline \multicolumn{2}{|l|}{ Education } \\
\hline No education & $69(43.9)$ \\
\hline Elementary & $32(20.4)$ \\
\hline High school & $25(16.7)$ \\
\hline College & $12(8)$ \\
\hline University & $12(8)$ \\
\hline \multicolumn{2}{|l|}{ Marital status } \\
\hline Single & $33(21)$ \\
\hline Married & $83(52.9)$ \\
\hline Divorced & $14(8.9)$ \\
\hline Widowed & $20(12.7)$ \\
\hline Monthly income & $1336.1 \pm 240.3$ \\
\hline \multicolumn{2}{|l|}{ Residence } \\
\hline Rural & $78(49.7)$ \\
\hline Surgery (yes) & $72(45.5)$ \\
\hline Duration of the disease (months) & $13.4 \pm 12.1$ \\
\hline Metastasis (yes) & $65(41.4)$ \\
\hline \multicolumn{2}{|l|}{ Diagnosis } \\
\hline Colorectal Ca & $30(20)$ \\
\hline Cervical Ca & $32(21.33)$ \\
\hline Lung Ca & $15(10)$ \\
\hline Blood related $\mathrm{Ca}$ & $36(24)$ \\
\hline Breast Ca & $37(24.7)$ \\
\hline \multicolumn{2}{|l|}{ Medications } \\
\hline 5-Fluorouracil & 68 \\
\hline Cisplatin & 47 \\
\hline Leucovorin & 79 \\
\hline Cyclophosphamide & 41 \\
\hline Doxorubicin & 39 \\
\hline Methotrexate & 45 \\
\hline Irinotecan & 27 \\
\hline Others & 31 \\
\hline
\end{tabular}

living with $\mathrm{Ca}$ helps to evaluate the effectiveness of our interventions. In developing countries including Ethiopia, HRQoL measurement is not performed routinely. This study aimed to determine the rate of HRQoL among Ca patients attending a teaching referral hospital in north Ethiopia. Based on GHS data, the rate of quality of life was found to be 52.7 (SD: 20.1) which was comparable from a result obtained in Addis Ababa, 52.5 (SD: 26.0) [11], but lower from the reference value [12]. In addition, QoL was quite small when compared 
TABLE 2: The mean global health status, functional scales, and symptom scales of cancer patients at UoGRH.

\begin{tabular}{lc}
\hline Scales & mean \pm SD \\
\hline Global health status & $52.7(20.1)$ \\
Functional scales & \\
Physical functioning & $53.27(22.9)$ \\
Role functioning & $43.32(26.7)$ \\
Social functioning & $46.31(25.5)$ \\
emotional functioning & $61(25.5)$ \\
Cognitive functioning & $59.31(43.6)$ \\
Symptoms scale & \\
Fatigue & $41.47(24.5)$ \\
Nausea and vomiting & $43.3(23.1)$ \\
Pain & $34.8(24.4)$ \\
Dyspnea & $34.8(29.2)$ \\
Insomnia & $42.1(33.3)$ \\
Appetite & $38.4(31.2)$ \\
Constipation & $40.6(31.2)$ \\
Diarrhea & $44.2(34.1)$ \\
Financial difficulties & $69.6(31.2)$ \\
\hline
\end{tabular}

with other studies from India, Melbourne, Nepal, and Brazil [13-15]. Low level of QoL in our study might be due to quality of care provided in the setup. The cancer center has been established only recently, as of 2015 , and advanced treatments including radiotherapy, adequate surgical procedure, and palliative care are yet to be started. In addition, patients are usually admitted once they are terminally ill. One study reiterated that level of care affects QoL [12]. Surgery has been linked with the improvement in QoL of patients in our study which is demonstrated by mean difference in QoL among individuals who underwent surgery.

The present study discovered that emotional and cognitive functions were among the highest functional status scores. They remain relatively unaffected. Emotions contain depression, worries, tension, and irritability whereas cognition evaluated the patients' level of concentration on things and their ability to remember. Patients report "not at all or a little" disturbance of emotion. Binary regression indicated that individuals with intact emotion were considered to have good QoL. In addition, a retrospective study in USA reported high cognitive functioning but low role functioning among hepatic Ca patients [16]. Rather, role functioning aspects such as doing daily activities and leisure were highly affected.

The most common compliance on symptom scale was nausea and vomiting followed by fatigue. Nauseas and vomiting are common in Ca patients due to the disease and therapy. The underutilization of antiemetics due to cost and nonadherence to guidelines might contribute to the prevalence of nauseas and vomiting [17]. Furthermore, fatigue was found to be the second most disabling symptom among Ca patients. It is resulted from the therapy including radiotherapy and chemotherapy as well as the disease state. Consequently, the QoL of patients is reduced as fatigue becomes sever [18]. Advanced disease states and the occurrence of psychosocial symptoms could aggravate the prevalence and severity of fatigue. Researches revealed that malignancy by itself could induce malaise and weakness [19].

The rate of role functioning was found to be different with respect to marital status. Single and married individuals had good role functioning as compared to divorced individuals $(p<0.05)$. Married persons tend to present early before metastasis and receive advanced care unlike other individuals. Other study also estimated that cancer survival rate was also affected by marital status. A comparative study indicated that widowed patients were found to be at greater risk of death relative to other groups [20]. With regard to GHS, the mean difference of GHS was significant based on the level of disease metastasis. Advanced diseases were found to reduce the GHS and emotional functioning of Ca patients. Accordingly, patients with no disease metastasis had high GHS as compared to metastasis $(p=0.03)$. Another finding on this study indicated that surgery showed a positive impact on the global health status of patients since it could bring a radical cure of the diseases if it is followed by adequate adjuvant therapy. But, it is difficult to generalize this finding for all forms of $\mathrm{Ca}$ as some cases favor improved quality of life when surgery preserves organs such as breast cancer and lung cancer so as to spare aesthetic values [21-23].

In the current study, multiple factors have been correlated with QoL of cancer patients. It was found that patients with affected physical functioning have a reduced quality of life. The global health QoL and functional status of cancer patients usually go parallel. For instance, a study measured the oropharyngeal neoplasia and its function and the global health status demonstrated that patients with limited or compromised oropharyngeal function were having poor QoL [24]. Patients with no history of vomiting were 2.5 more likely to have good QoL as compared to patients with vomiting history. Vomiting was found to affect routine activities of patients including household activities, feeding style, time allocation for social activities, and daily function and recreation [25]. In addition, patients with preserved social functioning are nearly four times more likely to have good QoL. Furthermore, patients with unaffected EF had 4.5 times good HRQoL as compared to affected HRQoL. A comparative study reported that emotional disturbance among cancer patients could lead to low level of global QoL $[26,27]$.

In general, the present study provided baseline information on the quality of life of Ca patients in developing country. However, it is limited to single institution as well as few sample size. In light of this, large studies are recommended to increase the generalizability of findings.

\section{Conclusion}

Health related quality of life of cancer patients was found to be low in Ethiopia. Patients with limited rate of disease metastasis had improved HRQoL. Further, the unmet needs of Ca patients and the level of satisfaction with the overall care were found to influence the extent of HRQoL. Therefore, early detection of neoplasm to arrest metastasis is warranted in order to achieve better QoL. In addition, addressing the unmet needs of these patients and ensuring higher satisfaction rate are recommended to maintain adequate HRQoL. 
TABLE 3: The mean difference QLQ scales versus sociodemographic characteristics.

\begin{tabular}{|c|c|c|c|c|c|c|}
\hline & QoL & $\mathrm{PF}$ & $\mathrm{RF}$ & $\mathrm{EF}$ & $\mathrm{CF}$ & SF \\
\hline \multicolumn{7}{|l|}{ Marital status } \\
\hline Single & $26.9(22.7)$ & $52.6(23.7)$ & $43(31.6)$ & $47.1(28.2)$ & $56.5(20)$ & $44.9(24.1)$ \\
\hline Married & $73.7(4.6)$ & $53.8(24.4)$ & $36.7(29.8)$ & $36.7(25.1)$ & $61.3(54.8)$ & $48.3(25.9)$ \\
\hline Divorced & $26.3(16.7)$ & $53(18.8)$ & $1.2(2.3)$ & $38.9(23.1)$ & $63(31.4)$ & $36.9(23.7)$ \\
\hline Widowed & $25(20.5)$ & $52.3(18.1)$ & $20(29.1)$ & $37.3(22.9)$ & $53.3(22.1)$ & $46.7(27.4)$ \\
\hline$p$ value & 0.871 & 0.989 & 0.02 & 0.25 & 0.85 & 0.475 \\
\hline \multicolumn{7}{|l|}{ Sex } \\
\hline Female & $74.7(4.6)$ & $50.3(23.4)$ & $48.2(29.9)$ & $37.6(24.4)$ & $56(24.1)$ & $71.5(29.1)$ \\
\hline Male & $25(20.2)$ & $56.9(21.8)$ & $37.3(27.8)$ & $41.3(26.8)$ & $63.4(59.5)$ & $67.2(33.7)$ \\
\hline$p$ value & 0.377 & 0.673 & 0.265 & 0.436 & 0.124 & 0.397 \\
\hline \multicolumn{7}{|l|}{ Education } \\
\hline No education & $80.8(4.9)$ & $51.7(24.9)$ & $50.7(10.8)$ & $36.1(23.1)$ & $57.2(25.2)$ & $44.9(25.3)$ \\
\hline Elementary & $33.1(19.3)$ & $48.4(21.5)$ & $38.1(31.1)$ & $37.2(26.1)$ & $48.5(24.8)$ & $47.4(19.3)$ \\
\hline High school & $25.9(18.9)$ & $59.4(20.9)$ & $37.3(35.3)$ & $48.7(30.8)$ & $74.9(65.3)$ & $41.6(30.1)$ \\
\hline College and above & $22.9(14.7)$ & $57.6(19.1)$ & $35.4(23.1)$ & $23.8(49.7)$ & $63(19.4)$ & $55.7(24.4)$ \\
\hline$p$ value & 0.361 & 0.152 & 0.57 & 0.175 & 0.128 & 0.214 \\
\hline \multicolumn{7}{|l|}{ Residence } \\
\hline Urban & $24.1(17.5)$ & $54.9(23.5)$ & $50.4(10.3)$ & $40.3(24.7)$ & $60(25.2)$ & $47(25.7)$ \\
\hline Rural & $84.1(3.4)$ & $51.4(22.1)$ & $35.6(28.3)$ & $38.1(26.4)$ & $58.5(57.4)$ & $45.6(25.5)$ \\
\hline$p$ value & 0.283 & 0.341 & 0.239 & 0.608 & 0.836 & 0.73 \\
\hline \multicolumn{7}{|c|}{ Duration of the disease } \\
\hline 0-12 months & $65.5(4.1)$ & $52.4(22.6)$ & $45.7(19.1)$ & $40.6(26.2)$ & $57.5(25.1)$ & $44.1(25.71)$ \\
\hline $13-24$ & $29.6(22.2)$ & $54.2(22.9)$ & $39.4(35.9)$ & $31.7(21.7)$ & $65.1(81.3)$ & $48.9(26.0)$ \\
\hline$\geq 25$ & $16.7(13.7)$ & $57.5(25.3)$ & $35.5(30)$ & $46.4(25.8)$ & $58.8(21.8)$ & $55.5(21.50)$ \\
\hline$p$ value & 0.412 & 0.531 & 0.162 & 0.11 & 0.689 & 0.217 \\
\hline \multicolumn{7}{|l|}{ Metastasis } \\
\hline Yes & $22.1(18.9)$ & $49.9(19.5)$ & $34.1(27.1)$ & $34.1(25.5)$ & $54.6(22.7)$ & $45.1(27.7)$ \\
\hline No & $92.1(5.1)$ & $55.8(24.9)$ & $50.34(29.8)$ & $53.2(25.3)$ & $62.9(54.3)$ & $47.2(23.8)$ \\
\hline$p$ value & 0.03 & 0.11 & 0.20 & 0.04 & 0.246 & 0.625 \\
\hline \multicolumn{7}{|l|}{ Surgery } \\
\hline Yes & $82.8(4.9)$ & $53.4(20.7)$ & $36.4(30.8)$ & $37.4(25.6)$ & $61.6(57.2)$ & $48.1(25.1)$ \\
\hline No & $24.5(19.5)$ & $53.2(24.8)$ & $49.7(10.2)$ & $40.95(25.4)$ & $57.2(25.6)$ & $44.6(25.9)$ \\
\hline$p$ value & 0.01 & 0.96 & 0.289 & 0.39 & 0.545 & 0.41 \\
\hline
\end{tabular}

PF: physical functioning, RF: role functioning, EF: emotional functioning, CF: cognitive functioning, and SF: social functioning.

\section{Abbreviations}

AOR: $\quad$ Adjusted Odds Ratio

AKA: $\quad$ Also Known As

Ca: $\quad$ Cancer

CF: $\quad$ Cognitive functioning

COR: $\quad$ Crude Odds Ratio

EF: Emotional functioning

GHS: Global health status

HRQoL: Health related quality of life

QoL: Quality of life

OS: Overall Survival

ORR: Overall Radiographic Response

PF: Physical functioning

PFS: Progression-Free Survival

SF: $\quad$ Social functioning

UoGRH: University of Gondar Referral Hospital.

\section{Data Availability}

All data generated or analyzed during this study are included in this article.

\section{Ethical Approval}

Ethical approval was sought from University of Gondar Hospital's clinical director.

\section{Conflicts of Interest}

The authors declare that they have no conflicts of interest.

\section{Authors' Contributions}

Tadesse Melaku Abegaz conceived the study, prepared the study protocol, analyzed the data, and wrote up the final 
TABLE 4: Association between functional and symptom scales and quality of life.

\begin{tabular}{|c|c|c|c|c|}
\hline \multirow{2}{*}{ Variables } & \multicolumn{2}{|c|}{ QoL } & \multirow{2}{*}{ COR 95\% CI } & \multirow{2}{*}{ AOR 95\% } \\
\hline & Affected & Not affected & & \\
\hline \multicolumn{5}{|l|}{ Sex } \\
\hline Male & $21(14)$ & $22(14.7)$ & 1 & 1 \\
\hline Females & $61(40.7)$ & $46(30.7)$ & $1.34[0.648-2.713]$ & $1.419[0.596-3.378]$ \\
\hline Age & $47.3(13.6)$ & $45.7(14.9)$ & $1.11[0.98-1.21]$ & $1.002[0.971-1.034]$ \\
\hline \multicolumn{5}{|l|}{ Residence } \\
\hline Rural & $57(38)$ & $21(14)$ & $0.877[0.429-1.79]$ & $1.482[0.630-3.484]$ \\
\hline Urban & $50(33.33)$ & $22(14.7)$ & 1 & 1 \\
\hline Duration of the $\mathrm{Dz}$ (month) & 11.91 & 13.27 & $0.11[0.97-1.1]$ & $1.001[0.959-1.045]$ \\
\hline \multicolumn{5}{|l|}{ Surgery } \\
\hline No & $58(38.7)$ & $20(13.33)$ & $1.433[0.7-2.95]$ & $1.084[0.447-2.633]$ \\
\hline Yes & $49(32.7)$ & $23(15.33)$ & 1 & 1 \\
\hline \multicolumn{5}{|l|}{ Metastasis } \\
\hline Yes & $49(32.7)$ & $24(16)$ & $0.728[0.351-1.511]$ & $0.590[0.235-1.479]$ \\
\hline No & $16(10.7)$ & $26(17.33)$ & 1 & 1 \\
\hline \multicolumn{5}{|l|}{ Physical functioning } \\
\hline No & $61(40.7)$ & $27(18)$ & 1 & 1 \\
\hline Yes & $46(30.7)$ & $16(10.7)$ & 1.357 [0.649-2.84] & $0.794[0.299-891]^{*}$ \\
\hline \multicolumn{5}{|l|}{ Role functioning } \\
\hline Yes & $42(28)$ & $21(14)$ & $0.646[0.315-1.33]$ & 0.655 [0.220-1.949] \\
\hline No & $65(43.3)$ & $21(14)$ & 1 & 1 \\
\hline \multicolumn{5}{|l|}{ Emotional functioning } \\
\hline Yes & $46(30.7)$ & $14(9.33)$ & 1 & 1 \\
\hline No & $61(40.7)$ & $29(19.3)$ & $1.682[0.788-3.59]$ & $4.426[2.890-6.613]^{*}$ \\
\hline \multicolumn{5}{|l|}{ Cognitive functioning } \\
\hline Yes & $36(24)$ & $9(6)$ & 1 & 1 \\
\hline No & $71(47.3)$ & $34(22.7)$ & $2.56[0.91-5.14]$ & $2.286[0.684-7.637]$ \\
\hline \multicolumn{5}{|l|}{ Social functioning } \\
\hline Yes & $36(24)$ & $7(4.7)$ & 1 & 1 \\
\hline No & $71(47.3)$ & $36(24)$ & $3.04[1.173-7.89]$ & $3.637[1.838-8.300]^{*}$ \\
\hline \multicolumn{5}{|l|}{ Fatigue } \\
\hline Yes & $57(38)$ & $14(9.3)$ & $2.45[1.15-5.25]$ & $1.999[0.488-8.188]$ \\
\hline No & $50(33.3)$ & $28(18.7)$ & 1 & 1 \\
\hline \multicolumn{5}{|l|}{ Vomiting } \\
\hline Yes & $55(36.7)$ & $18(12)$ & 1 & 1 \\
\hline No & $52(34.7)$ & $25(16.7)$ & $1.55[0.756-3.21]$ & $2.655[1.839-8.397]^{* *}$ \\
\hline \multicolumn{5}{|l|}{ Pain } \\
\hline Yes & $54(36)$ & $28(18.7)$ & 1 & 1 \\
\hline No & $53(35.33)$ & $15(10)$ & $0.529[0.251-1.14]$ & $0.639[0.217-1.881]$ \\
\hline \multicolumn{5}{|l|}{ Dyspnea } \\
\hline Yes & $36(24)$ & $20(13.33)$ & $0.614[0.296-1.271]$ & $0.867[0.308-2.438]$ \\
\hline No & $71(47.33)$ & $23(15.33)$ & 1 & 1 \\
\hline \multicolumn{5}{|l|}{ Appetite } \\
\hline Yes & $38(25.33)$ & $11(7.33)$ & 1 & 1 \\
\hline No & $69(46)$ & $32(21.33)$ & $1.762[0.782-3.973]$ & $1.784[0.487-6.532]$ \\
\hline \multicolumn{5}{|l|}{ Constipation } \\
\hline Yes & $36(24)$ & $14(9.33)$ & $1.14[0.476-2.161]$ & $0.600[0.165-2.180]$ \\
\hline No & $71(47.33)$ & $29(19.33)$ & 1 & 1 \\
\hline \multicolumn{5}{|l|}{ Diarrhea } \\
\hline Yes & $60(40)$ & $24(16)$ & 1 & 1 \\
\hline No & $47(31.33)$ & $19(12.7)$ & 0.957 [0.467-1.97] & $1.253[0.447-3.514]$ \\
\hline
\end{tabular}


TABLE 4: Continued.

\begin{tabular}{|c|c|c|c|c|}
\hline \multirow{2}{*}{ Variables } & \multicolumn{2}{|c|}{ QoL } & \multirow{2}{*}{ COR 95\% CI } & \multirow{2}{*}{ AOR 95\% } \\
\hline & Affected & Not affected & & \\
\hline \multicolumn{5}{|c|}{ Financial problem } \\
\hline Yes & $35(23.33)$ & $11(7.33)$ & 1 & 1 \\
\hline No & $71(47.33)$ & $33(22)$ & $1.81[0.787-4.191]$ & $2.240[0.711-7.064]$ \\
\hline \multicolumn{5}{|c|}{ Need required } \\
\hline Yes & $59(39.33)$ & $30(20)$ & 0.67 [0.54-0.79] & $0.85[0.80-0.95]^{*}$ \\
\hline No & $26(17.33)$ & $35(23.34$ & 1 & 1 \\
\hline \multicolumn{5}{|c|}{ Level of satisfaction } \\
\hline Low & $72(48)$ & $25(16.67)$ & $0.73[0.62-0.89]$ & $0.82[0.76-0.93]^{*}$ \\
\hline High & $34(22.67)$ & $19(12.67)$ & 1 & 1 \\
\hline
\end{tabular}

${ }^{*}$ Significant at 0.05 levels; ${ }^{* *}$ significant at 0.01 levels.

manuscript. Begashaw Melaku Gebresillassie and Asnakew Achaw Ayele interpreted and analyzed the data and wrote the initial draft of manuscript. All the authors read and approved the final manuscript and agreed to be accountable for all aspects of the work.

\section{Acknowledgments}

The authors would like to acknowledge the University of Gondar, College of Medicine and Health Science, for the overall support.

\section{References}

[1] C. Fitzmaurice, C. Allen, RM. Barber et al., "Global, regional, and national cancer incidence, mortality, years of life lost, years lived with disability, and disability-adjusted life-years for 32 cancer groups, 1990 to 2015: a systematic analysis for the global burden of disease study," JAMA oncology, vol. 3, no. 4, pp. 524548, 2017.

[2] A. Jemal, F. Bray, M. M. Center, J. Ferlay, E. Ward, and D. Forman, "Global cancer statistics," CA: A Cancer Journal for Clinicians, vol. 61, no. 2, pp. 69-90, 2011.

[3] A. Jemal, F. Bray, D. Forman et al., "Cancer burden in Africa and opportunities for prevention," Cancer, vol. 118, no. 18, pp. 43724384, 2012.

[4] P. Pisani, "The cancer burden and cancer control in developing countries," Environmental Health: A Global Access Science Source, vol. 10, no. 1, article no. S2, 2011.

[5] A. Misganaw, D. H. Mariam, A. Ali, and T. Araya, "Epidemiology of major non-communicable diseases in Ethiopia: a systematic review," Journal of Health, Population and Nutrition, vol. 32, no. 1, pp. 1-13, 2014.

[6] B. Tefera, M. Assefa, B. Abebe, and D. Rauch, "Patterns of Cancer in University of Gondar Hospital: North-West Ethiopia," Journal of Oncology Medicine and Practice, vol. 1, no. 106, 2016, cancer in Gondar.

[7] L. Dirven, J. A. Koekkoek, J. C. Reijneveld, and M. J. Taphoorn, "Health-related quality of life in brain tumor patients: as an endpoint in clinical trials and its value in clinical care," Expert Review of Quality of Life in Cancer Care, vol. 1, no. 1, pp. 37-44, 2016.

[8] P. Y. Wen, D. R. Macdonald, D. A. Reardon et al., "Updated response assessment criteria for high-grade gliomas: response assessment in neuro-oncology working group," Journal of Clinical Oncology, vol. 28, no. 11, pp. 1963-1972, 2010.

[9] K. Mystakidou, E. Tsilika, E. Parpa, O. Kalaidopoulou, V. Smyrniotis, and L. Vlahos, "The EORTC core quality of life questionnaire (QLQ-C30, version 3.0) In terminally ill cancer patients under palliative care: Validity and reliability in a hellenic sample," International Journal of Cancer, vol. 94, no. 1, pp. 135139, 2001.

[10] H. Michelson, C. Bolund, B. Nilsson, and Y. Brandberg, "HealthRelated Quality of Life measured by the EORTC QLQ-C30 Reference values from a large sample of the Swedish population," Acta Oncologica, vol. 39, no. 4, pp. 477-484, 2000.

[11] Assessing the quality of life among patients with breast cancer at tikur anbassa specialized hospital, Ethiopia: 2016.

[12] B. Zhang, M. E. Nilsson, and H. G. Prigerson, "Factors important to patients' quality of life at the end of life," JAMA Internal Medicine, vol. 172, no. 15, pp. 1133-1142, 2012.

[13] B. Dubashi, E. Vidhubala, S. Cyriac, and T. Sagar, "Quality of life among young women with breast cancer: Study from a tertiary cancer institute in south India," Indian Journal of Cancer, vol. 47, no. 2, pp. 142-147, 2010.

[14] B. Grabsch, D. M. Clarke, A. Love et al., "Psychological morbidity and quality of life in women with advanced breast cancer: a cross-sectional survey.", Palliative \& Supportive Care, vol. 4, no. 1, pp. 47-56, 2006.

[15] S. Manandhar, D. S. Shrestha, P. Taechaboonsermsk, S. Siri, and J. Suparp, "Quality of life among breast cancer patients undergoing treatment in national cancer centers in Nepal," Asian Pacific Journal of Cancer Prevention, vol. 15, no. 22, pp. 9753-9757, 2014.

[16] A. Meier, A. Yopp, H. Mok, P. Kandunoori, J. Tiro, and A. G. Singal, "Role functioning is associated with survival in patients with hepatocellular carcinoma," Quality of Life Research, vol. 24, no. 7, pp. 1669-1675, 2015.

[17] P. J. E. Miller, S. Balu, D. Buchner, M. S. Walker, E. J. Stepanski, and L. S. Schwartzberg, "Willingness to pay to prevent chemotherapy induced nausea and vomiting among patients with breast, lung, or colorectal cancer," Journal of Medical Economics, vol. 16, no. 10, pp. 1179-1189, 2013.

[18] G. Karthikeyan, D. Jumnani, R. Prabhu, U. K. Manoor, and S. S. Supe, "Prevalence of fatigue among cancer patients receiving various anticancer therapies and its impact on Quality of Life: A cross-sectional study," Indian Journal of Palliative Care, vol. 18, no. 3, pp. 165-175, 2012.

[19] P. Stone, M. Richards, R. A'Hern, and J. Hardy, "A study to investigate the prevalence, severity and correlates of fatigue 
among patients with cancer in comparison with a control group of volunteers without cancer," Annals of Oncology, vol. 11, no. 5, pp. 561-567, 2000.

[20] A. A. Aizer, M.-H. Chen, E. P. McCarthy et al., "Marital status and survival in patients with cancer," Journal of Clinical Oncology, vol. 31, no. 31, pp. 3869-3876, 2013.

[21] M. Akca, A. Ata, E. Nayir, S. Erdogdu, and A. Arican, "Impact of Surgery Type on Quality of Life in Breast Cancer Patients," The Journal of Breast Health, vol. 10, no. 4, pp. 222-228, 2014.

[22] E. Hermans, P. M. Van Schaik, H. A. Prins, M. F. Ernst, P. J. L. Dautzenberg, and K. Bosscha, "Outcome of colonic surgery in elderly patients with colon cancer," Journal of Oncology, Article ID 865908, 2010.

[23] J. Y. Kim, V. Sun, D. J. Raz et al., “The impact of lung cancer surgery on quality of life trajectories in patients and family caregivers," Lung Cancer, vol. 101, pp. 35-39, 2016.

[24] P. A. Borggreven, I. M. Verdonck-De Leeuw, M. J. Muller et al., "Quality of life and functional status in patients with cancer of the oral cavity and oropharynx: Pretreatment values of a prospective study," European Archives of Oto-Rhino-Laryngology, vol. 264, no. 6, pp. 651-657, 2007.

[25] C. M. Lindley, J. D. Hirsch, C. V. O’Neill, M. C. Transau, C. S. Gilbert, and J. T. Osterhaus, "Quality of life consequences of chemotherapy-induced emesis," Quality of Life Research, vol. 1, no. 5, pp. 331-340, 1992.

[26] B. H. Lue, T. S. Huang, and H. J. Chen, "Physical distress, emotional status, and quality of life in patients with nasopharyngeal cancer complicated by post-radiotherapy endocrinopathy," International Journal of Radiation Oncology • Biology $\bullet$ Physics, vol. 70, no. 1, pp. 28-34, 2008.

[27] A. Tavoli, A. Montazeri, R. Roshan, Z. Tavoli, and M. Melyani, "Depression and quality of life in cancer patients with and without pain: The role of pain beliefs," BMC Cancer, vol. 8, article no. 177, 2008. 


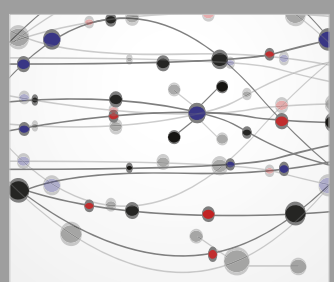

The Scientific World Journal
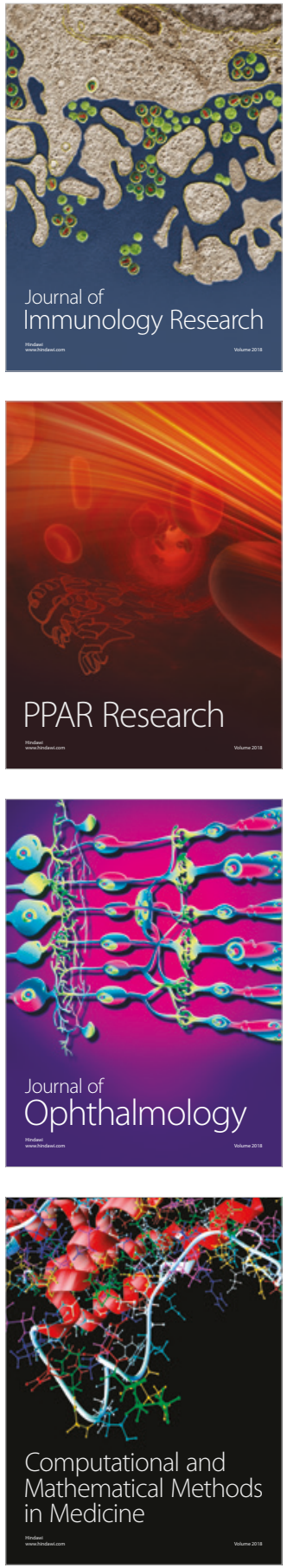

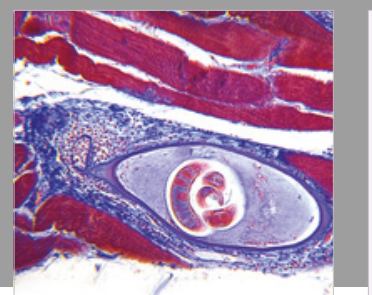

Gastroenterology Research and Practice

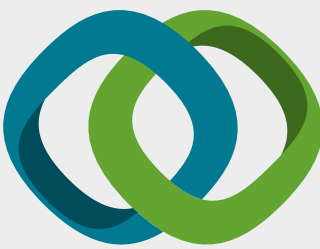

\section{Hindawi}

Submit your manuscripts at

www.hindawi.com
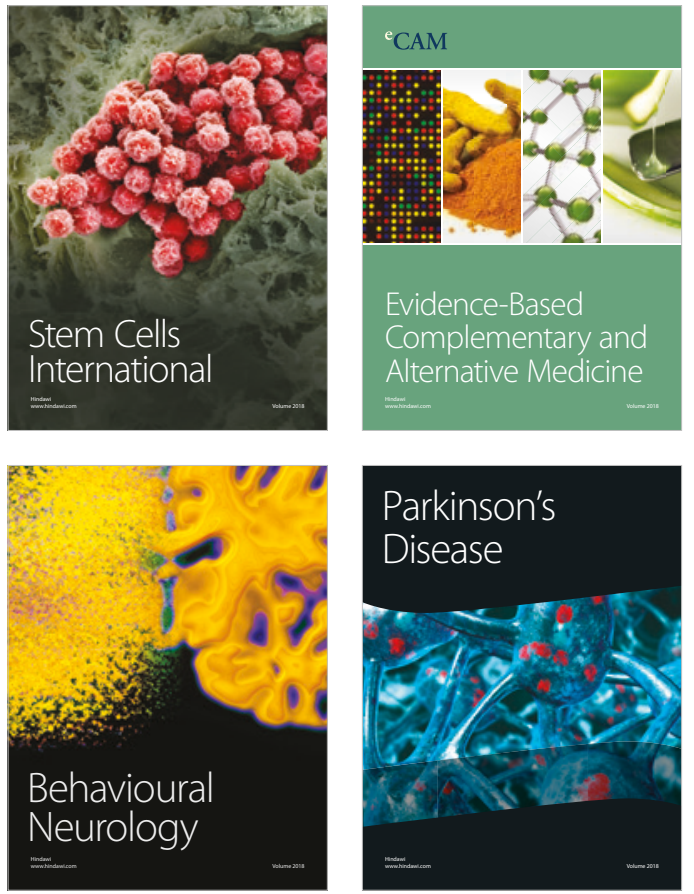

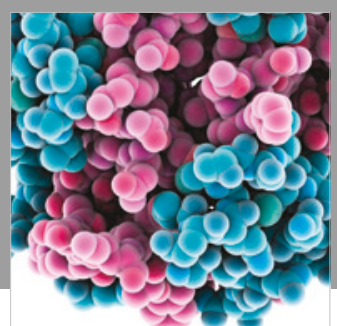

ournal of

Diabetes Research

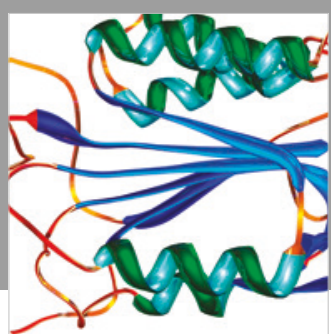

Disease Markers
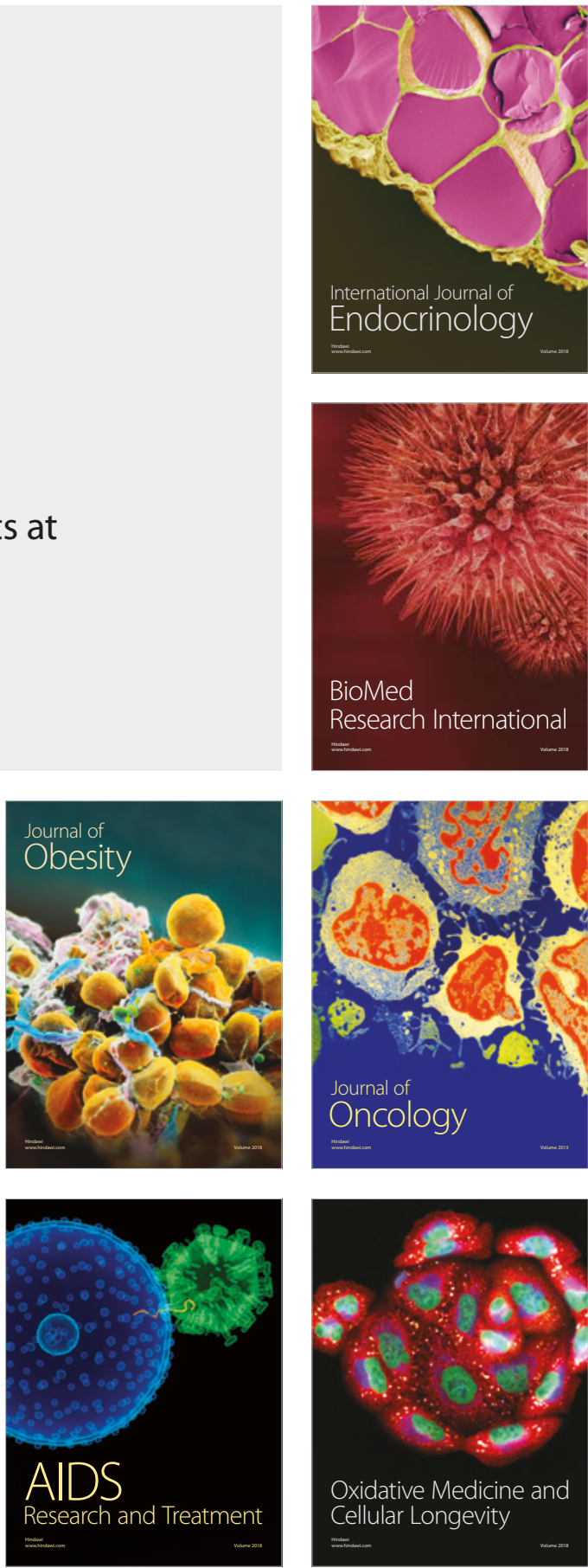